\title{
ALBINO GOPHERS
}

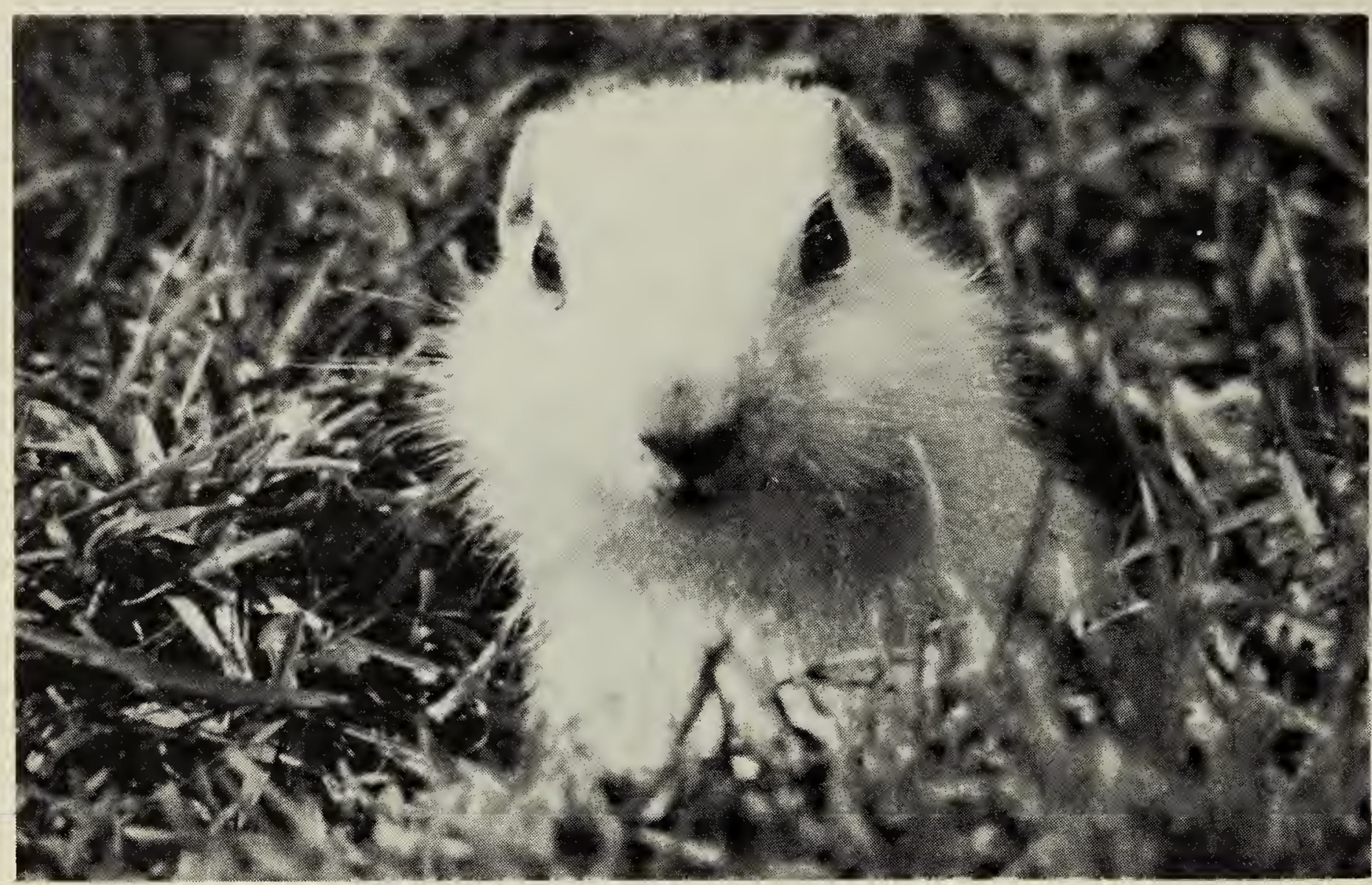

Photo by Joan Dew

Albino gopher at Lacombe, Alberta

A family of albino gophers (Richardson's Ground Squirrel) was noticed on June 6 on a farm a few miles north of Lacombe, Alberta, land location SW15-41-26-W4. At this time all four of them were around one hole but a few days later they moved into separate holes. I first saw them on June 12 when I observed that they were pure white except for a small black patch at the tip of the tail and that their eyes were pink. They seemed considerably tamer than normally coloured gophers and with a little patience I managed to get very close to one and even touched it without alarming it. The enclosed photograph is a picture of one of these gophers.-Joan Dew, Box 394, Lacombe, Alberta.

\section{POSSIBLE OCCURRENCE OF COUGAR NEAR FORT SMITH, N.W.T.}

by E. Kuyt, Canadian Wildlife Service, Fort Smith, N.W.T.

Mr. D. Bohnet of Fort Smith, N.W.T., informed me that on August 30, 1970 he and his wife had briefly observed two cougars (Felis concolor) about five miles south of the Parson's Lake fire lookout tower in the northern part of Wood Buffalo National Park. The geographic location of the sighting would be about $59^{\circ} 50^{\prime} \mathrm{N}, 112^{\circ} 25^{\prime} \mathrm{W}$. The animals were seen at a distance of about 50 yards and appeared to be of equal size. Mr. Bohnet thought that in size they approximated that of a large dog. He did not see any spots or markings but did note the animals' long tails and general light tan colouration.

Another resident of Fort Smith, Mr. M. Hewitt, had told me some time ago that on March 17, 1967 he had seen a large cat standing on the edge of the road, about 12 miles north of $\mathrm{Hay}$ 
Camp, Wood Buffalo National Park. Mr. Hewitt thought it was easily the largest lynx he had ever seen but as he approached in his car the animal turned and bounded across the ditch into the woods, and it was then that Mr. Hewitt observed the cat's long tail. Mr. Hewitt believed the animal to be about the size of his mediumsize Alsatian dog, although somewhat more stocky in build.

I also recalled a much earlier report of a cougar and I was able to contact two of the observers who were still residing in Forth Smith. Of these two observers, Mrs. D. Fowler had never seen a cougar before but Mr. G. Dexter, the other observer, had seen cougar in British Columbia. Mrs. Fowler informed me that her neighbour had first seen the cougar in the summer of 1962 near her residence at the foot of Axe Handle Hill in Fort Smith. Mr. Dexter had been summoned to kill the animal which had taken refuge in a poplar. When Mr. Dexter drove up, the cougar jumped from the tree and bounded up Axe Handle Hill, to the chagrin of some of the by. standers but to the relief of the others. The cougar was not seen again but its tracks, easily visible in the sandy soil, were examined by Mr. G. Douglas, then Acting Superintendent of Game for the N.W.T.
The presence of cougar in our area niust be regarded as exceedingly rare. It is of considerable interest, though, that white-tailed deer (Odocoileus virginianus) have recently increased in the Fort Smith area. I previously reported two sightings of these deer within 12 miles of Fort Smith as well as observations of deer tracks (Kuyt, Blue Jay 24(4), 1966). Since then, I have obtained nine additional sight reports of white-tailed deer (three each in 1967, 1968 and 1969). These observations were made at widely scattered points, varying from 0-65 air miles from Fort Smith and included sightings of male and female deer as well as fawns. Duplication of observations may have occurred in one or two sightings. A mule deer (Odocoileus hemionus) was observed in late July, 1968 about 65 miles south of Fort Smith. There is no doubt, then, that deer, one of the favourite foods of cougar, are present in small numbers in our area. With varying hare (Lepus americanus) currently nearing the peak of their cyclic abundance, alternate food resources are also available for cougar. It is hoped that in our area where livestock are practically non-existent, cougar will remain unmolested. This magnificent carnivore would be a valuable addition to the fauna of Wood Buffalo National Park.

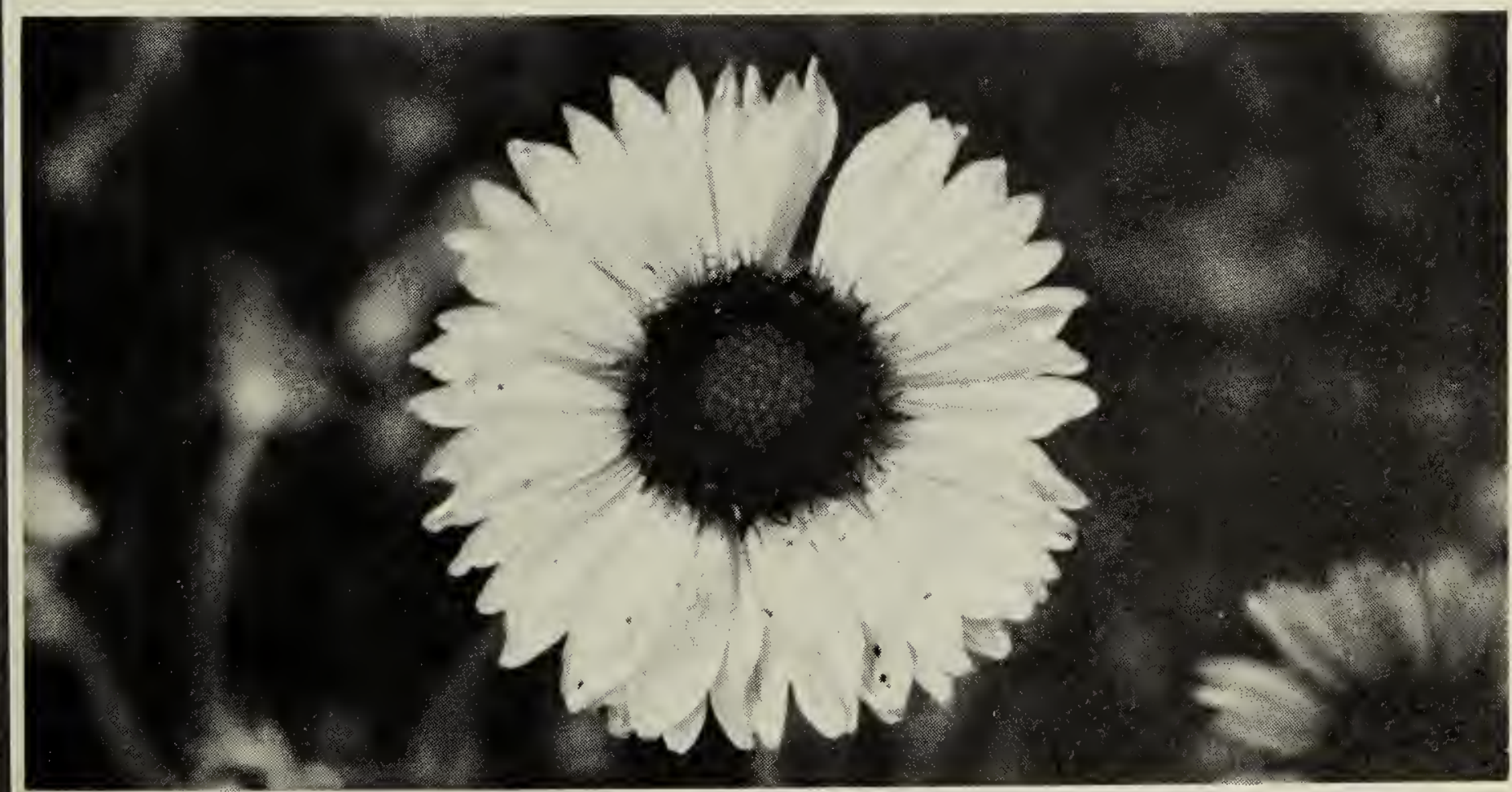

Gaillardia

Photo by Fenton Vance 